\title{
Nasal high-flow oxygen therapy in patients with hypoxic respiratory failure: effect on functional and subjective respiratory parameters compared to conventional oxygen therapy and non-invasive ventilation (NIV)
}

Norbert Schwabbauer', Björn Berg ${ }^{1}$, Gunnar Blumenstock², Michael Haap ${ }^{1}$, Jürgen Hetzel ${ }^{3}$ and Reimer Riessen ${ }^{1 *}$

\begin{abstract}
Background: Aim of the study was to compare the short-term effects of oxygen therapy via a high-flow nasal cannula (HFNC) on functional and subjective respiratory parameters in patients with acute hypoxic respiratory failure in comparison to non-invasive ventilation (NIV) and standard treatment via a Venturi mask.

Methods: Fourteen patients with acute hypoxic respiratory failure were treated with $\mathrm{HFNC}\left(\mathrm{FiO}_{2}\right.$ 0.6, gas flow $55 \mathrm{l} / \mathrm{min}), \mathrm{NIV}\left(\mathrm{FiO}_{2} \mathrm{0.6}\right.$, PEEP $5 \mathrm{~cm} \mathrm{H} \mathrm{H}_{2} \mathrm{O} \mathrm{Hg}$, tidal volume $6-8 \mathrm{ml} / \mathrm{kg}$ ideal body weight, ) and Venturi mask $\left(\mathrm{FiO}_{2}\right.$ 0.6, oxygen flow $15 \mathrm{l} / \mathrm{min}$,) in a randomized order for $30 \mathrm{~min}$ each. Data collection included objective respiratory and circulatory parameters as well as a subjective rating of dyspnea and discomfort by the patients on a 10-point scale. In a final interview, all three methods were comparatively evaluated by each patient using a scale from 1 (=very good) to 6 (=failed) and the patients were asked to choose one method for further treatment.

Results: $\mathrm{PaO}_{2}$ was highest under NIV $(129 \pm 38 \mathrm{mmHg})$ compared to HFNC (101 $\pm 34 \mathrm{mmHg}, \mathrm{p}<0.01 \mathrm{vs}$. NIV $)$ and VM $(85 \pm 21 \mathrm{mmHg}, \mathrm{p}<0.001 \mathrm{vs.}$ NIV, $p<0.01$ vs. HFNC, ANOVA). All other functional parameters showed no relevant differences. In contrast, dyspnea was significantly better using a HFNC (2.9 $\pm 2.1,10$-point Borg scale) compared to NIV $(5.0 \pm 3.3, \mathrm{p}<0.05)$, whereas dyspnea rating under HFNC and VM $(3.3 \pm 2.3)$ was not significantly different. A similar pattern was found when patients rated their overall discomfort on the 10 point scale: HFNC $2.7 \pm 1.8$, VM $3.1 \pm 2.8$ (ns vs. HFNC), NIV $5.4 \pm 3.1$ ( $p<0.05$ vs. HFNC). In the final evaluation patients gave the best ratings to HFNC $2.3 \pm 1.4$, followed by VM $3.2 \pm 1.7$ (ns vs. HFNC) and NIV $4.5 \pm 1.7$ ( $p<0.01$ vs. HFNC and $p<0.05$ vs. VM). For further treatment 10 patients chose HFNC, three VM and one NIV.
\end{abstract}

Conclusions: In hypoxic respiratory failure HFNC offers a good balance between oxygenation and comfort compared to NIV and Venturi mask and seems to be well tolerated by patients.

Trial registration: German clinical trials register: DRKS00005132.

Keywords: Respiratory failure, Oxygen, High-flow nasal cannula, Non-invasive ventilation, Venturi mask

\footnotetext{
* Correspondence: reimer.riessen@med.uni-tuebingen.de

'Department of Internal Medicine, Medical Intensive Care Unit, University of

Tübingen, Otfried-Müller-Str, 10, Tübingen 72076, Germany

Full list of author information is available at the end of the article
} 


\section{Background}

Acute respiratory failure can be functionally classified as hypoxic type 1 and hypercapnic type 2 respiratory failure. Hypercapnic respiratory failure is a clear indication for non-invasive or invasive ventilatory support, whereas the administration of oxygen is the primary treatment in mild and moderate hypoxic respiratory failure [1,2]. With additional oxygen supply, the fraction of oxygen in inspired air $\left(\mathrm{FiO}_{2}\right)$ is raised above that of the normal atmosphere to avoid or correct hypoxemia with subsequent tissue hypoxia [3].

Oxygen applicators can be basically divided into lowflow and high-flow devices [4]. Low-flow devices such as nasal catheters, cannulas or simple masks deliver a limited flow of $100 \%$-oxygen $(1-15 \mathrm{l} / \mathrm{min}$ maximum) which is mixed with the total inspiratory gas flow of the patient. The effective inspiratory oxygen concentration $\left(\mathrm{EIO}_{2}\right)$ depends on the respiratory flow and breathing pattern of each individual patient and therefore is difficult to estimate in advance [5].

Modern high-flow nasal cannula (HFNC) devices equipped with an active humidification chamber can provide gas flow rates up to $70 \mathrm{l} / \mathrm{min}$, which are higher than the patient's respiratory flow, and therefore allow a controlled delivery of a defined $\mathrm{FiO}_{2}$ up to 1.0, independent of the breathing pattern of each patient [6]. HFNC might also reduce the work of breathing [7]. HFNC requires active heating and humidification of the respiratory gases in order to prevent damage of the respiratory epithelium and reduces discomfort during therapy [8,9]. Lastly, HFNC is increasingly used in intensive care and emergency medicine $[10,11]$.

Oxygen can also be applied via nasal, facial or full-face masks using non-invasive ventilation (NIV). NIV has the advantage that the use of positive end-expiratory pressure (PEEP) can induce alveolar recruitment and improve hypoxemia by reducing shunts. Despite these theoretical advantages, the use of NIV in hypoxemic respiratory failure is much less established than it is in hypercapnic respiratory failure [12-14].

In this study we compared oxygen therapy with HFNC to NIV and Venturi mask in patients with acute hypoxic respiratory failure. We used a short-term experimental protocol with a focus on respiratory and circulatory parameters in combination with subjective ratings by the patients. We specifically tried to evaluate HFNC in terms of patient comfort and relief of dyspnea in comparison to established standard methods.

\section{Methods}

\section{Patients}

Patients with primary hypoxic respiratory failure $\left(\mathrm{PaO}_{2}<\right.$ $55 \mathrm{mmHg}$ breathing room air) of acute onset admitted to the Medical ICU were enrolled in the present study from March 2009 to March 2011. Patients were screened for participation in the study during morning rounds and during the day shift and received a standard work-up for respiratory failure including a chest $x$-ray. The $\mathrm{PaO}_{2}$ of $<55 \mathrm{mmHg}$ breathing room air was chosen as a compromise between the severity of respiratory failure and patient safety during the study protocol. Exclusion criteria were defined as follows: clinical evidence for cardiac pulmonary edema (history, clinical examination, chest $\mathrm{x}$-ray, echocardiography), COPD and/or ventilatory failure (history, clinical examination, chest $\mathrm{x}$-ray, $\mathrm{PaCO} 2>$ $50 \mathrm{mmHg}$ ), hemodynamic instability, contraindications to NIV, impaired consciousness or disorientation, and inability to give informed consent. The Ethics Committee of the University of Tübingen approved the protocol. All subjects gave informed written consent and underwent the standard procedures of the protocol, including medical history, review of medications, physical examination and routine blood tests.

\section{Study protocol}

The order of the experimental protocol was randomly assigned (Figure 1). The assignment of patients to the sequence in which the three oxygen applicators were applied was randomized. Each intervention was preceded by a 15minute baseline period, in which oxygen was administered via conventional nasal prongs. The gas flow was set to achieve a peripheral oxygen saturation $\left(\mathrm{SpO}_{2}\right)$ of $\geq 88 \%$. This gas flow was used in all subsequent baseline phases. The interventions themselves had a duration of $30 \mathrm{~min}$.

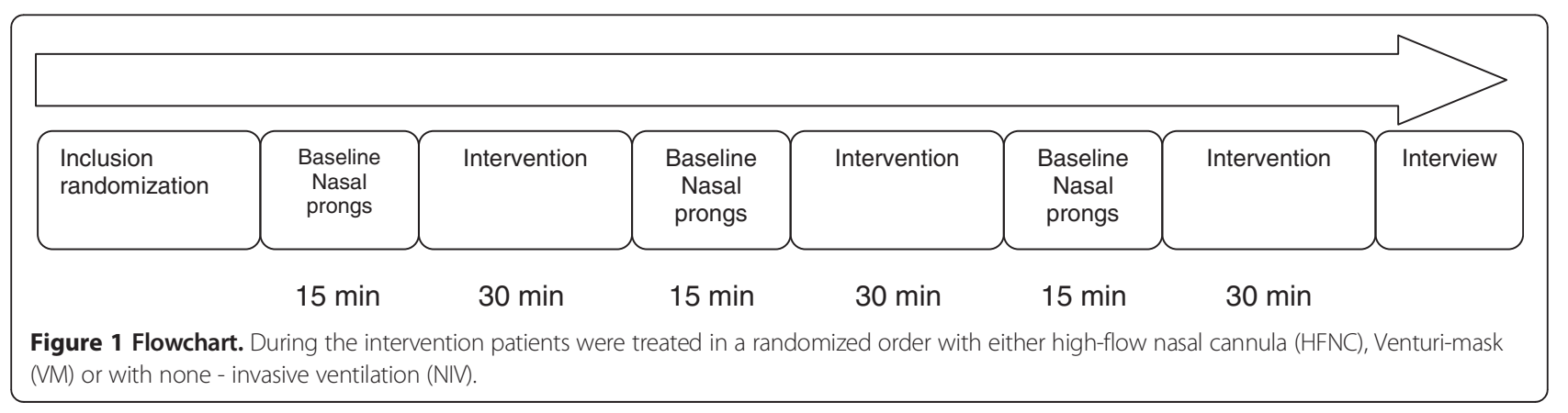


The patients were allowed to stop an intervention prematurely (e.g. if they did not tolerate an oxygen applicator).

\section{Measurements}

After each baseline and intervention phase, the following parameters were measured: arterial blood gases, heart rate, blood pressure, respiratory rate, and peripheral oxygen saturation. All data were documented in the electronic Patient Data Management System (PDMS, CareVue ${ }^{\circ}$ Philips).

In addition, after each intervention patients were asked to grade the severity of their dyspnea on a modified Borg category ratio 10 (CR10) scale. Low numbers indicated little dyspnea, high numbers severe dyspnea. A similar 10-point numeric rating scale (NRS) was used to grade general discomfort related to the oxygen applicator with low numbers indicating low discomfort. After the third intervention, the patients were asked for a global rating of all three applicators using a six-point rating system $(1=$ very good to $6=$ failed). The patients could also choose one oxygen applicator for further treatment.

The primary endpoint was the $\mathrm{PaO} 2$. Secondary endpoints were respiratory rate, dyspnea (Borg-scale), discomfort (10-point NRS), PaCO2, heart rate, blood pressure, $\mathrm{SpO}_{2}$, global rating, and patient preference.

\section{Oxygen applicators used}

Standard nasal prongs (AsidBonz, Herrenberg, Germany) with an oxygen flow of $4-12 \mathrm{~L} / \mathrm{min}$. were used for the baseline period (Table 1). For conventional controlled oxygen administration, patients received a Venturi mask (Unomedical, Birkerød, Denmark) with an oxygen flow of $15 \mathrm{~L} / \mathrm{min}$ and $\mathrm{FiO}_{2}$ of 0.6. Both oxygen applicators were used together with a closed sterile water system for conventional bubble humidification at room temperature (Respiflo, Covidien, Neustadt/Donau, Germany).

High - flow oxygen therapy via a HFNC (OptiFlow', Fisher \& Paykel Healthcare Welzheim, Germany) was administered with a $\mathrm{FiO}_{2} 0.6$ and a gas flow of $55 \mathrm{~L} / \mathrm{min}$ using an active respiratory gas humidifier (MR 850, setting "invasive ventilation", Fisher \& Paykel Healthcare, Welzheim, Germany).

For NIV, intensive care ventilators in the pressure support mode were used according to the current guideline for NIV in respiratory failure [14]. In all patients $\mathrm{FiO}_{2}$ was set to 0.6 and PEEP to $5 \mathrm{~cm} \mathrm{H}_{2} \mathrm{O}$. Five patients were treated with a ventilator equipped specific NIV-mode (Servo i, Maquet, Rastatt, Germany), 9 patients were treated with a ventilator without a NIVmode (Dräger Evita 4, Dräger, Lübeck, Germany). The pressure support above PEEP was adjusted individually to achieve a tidal volume of $6-8 \mathrm{ml} / \mathrm{kg}$ ideal body weight. The interface between the patient and the ventilator was a commercially available mouth/nose mask (UltraMirage NV, Resmed Martinsried, Germany). The ventilators were also equipped with an active respiratory gas humidifier (MR 850, setting NIV, Fisher \& Paykel Healthcare Welzheim, Germany).

\section{Statistics}

Data are presented as means \pm standard deviations. Repeated measures ANOVA was used to assess the measurements taken under the three different conditions (VM, HFNC, NIV). Statistical significance was set at $\mathrm{p}<0.05$. Post-hoc pair wise comparisons using the paired test were conducted only in the case of an overall significant ANOVA result. A sample size of 14 patients had a priori been estimated to have $80 \%$ power to detect a clinically relevant difference of $10 \mathrm{mmHg}$ in $\mathrm{PaO} 2$ across the 3 conditions given an SD of $35 \mathrm{~mm} \mathrm{Hg}$ at each level and a between level correlation of 0.80 . Likewise, for both the modified Borg CR10 dyspnea scale and the patient discomfort 10-point numeric rating scale, a relevant difference of 1 scale point across the conditions given an SD of 2.5 points at each level and an between level correlation of 0.60 would be detected with $80 \%$ power, when the sample size was 14 . All analyses were performed with the JMP ${ }^{\circ}$ 9.0 statistical software (SAS Institute, Cary, NC).

\section{Results}

Fourteen patients with hypoxic type 1 respiratory failure were enrolled in the study (Table 1). In three patients the NIV intervention phase had to be stopped prematurely because the patients did not tolerate the NIV mask. We did not observe any evidence for patientventilator asynchronicity during the NIV intervention phase. In one case, the blood gas analysis at the end of the NIV intervention phase could not be collected in time due to a technical problem. Measurements during the three baseline periods did not show any significant differences (Table 2).

$\mathrm{PaO}_{2}$ with NIV $(129 \pm 38 \mathrm{mmHg})$ was significantly higher than $\mathrm{PaO}_{2}$ with HFNC $(101 \pm 34 \mathrm{mmHg}, \mathrm{p}<0.01)$ (Table 2). In contrast to NIV and HFNC, $\mathrm{PaO}_{2}$ with VM was significantly lower $(85 \pm 21 \mathrm{mmHg}, \mathrm{P}<0.001$ vs. NIV, $\mathrm{p}<0.01$ vs. HFNC). The respiratory rate was slightly, but significantly lower under NIV vs. VM ( $24 \pm$ 9 vs. $28 \pm 8, \mathrm{p}<0,01)$. All other cardiorespiratory and blood gas parameters showed no relevant differences (Table 2).

Subjective rating of dyspnea expressed on a 10-point Borg scale was lowest under HFNC $(2.9 \pm 2.1)$, but not significantly different to VM $(3.3 \pm 2.3)$ (Table 2). Dyspnea with NIV, however, was rated significantly higher than with HFNC $(5.0 \pm 3.3, \mathrm{p}<0.05)$. Similarily, patient discomfort was lowest with HFNC $(2.7 \pm 1.8)$ and VM $(3.1 \pm 2.8$, ns vs. HFNC), and highest with NIV $(5.4 \pm 3.1$ $\mathrm{p}<0.05$ vs. HFNC). 
Table 1 Patients characteristics

\begin{tabular}{|c|c|c|c|c|c|c|c|c|}
\hline No & Diagnosis & $\begin{array}{c}\text { Age } \\
\text { [years] }\end{array}$ & $\begin{array}{c}\mathrm{BMI} \\
{\left[\mathrm{kg} / \mathrm{m}^{2}\right]}\end{array}$ & SAPS II & $\begin{array}{c}\text { Baseline } \mathrm{O}_{2} \text {-flow } \\
\text { [L/min] }\end{array}$ & $\begin{array}{l}\text { Measurement in days } \\
\text { after ICU-admission }\end{array}$ & $\begin{array}{l}\text { Mech. venti. during ICU stay } \\
\text { (no/after the study) }\end{array}$ & $\begin{array}{l}\text { Hospital } \\
\text { survival }\end{array}$ \\
\hline 1 & Idiopathic pneumonia syndrome & 29 & 27 & 56 & 10 & 0 & 1 day, after & No \\
\hline 2 & Pneumonia (respiratory syncytial virus) & 69 & 34 & 55 & 7 & 6 & no & Yes \\
\hline 3 & Pneumonia (Strep. pneumoniae) & 82 & 21 & 29 & 8 & 10 & no & Yes \\
\hline 4 & Pneumonia & 72 & 30 & 36 & 6 & 1 & no & Yes \\
\hline 5 & Pneumonia (Staph. aureus) & 78 & 30 & 48 & 12 & 15 & no & Yes \\
\hline 6 & Pneumonia, pleural mesothelioma & 71 & 26 & 54 & 4 & 1 & no & Yes \\
\hline 7 & Pneumonia & 76 & 28 & 55 & 6 & 0 & no & Yes \\
\hline 8 & Pneumonia & 50 & 25 & 45 & 6 & 1 & no & Yes \\
\hline 9 & Adenocarcinoma lung & 59 & 19 & 29 & 7 & 7 & 11 days, after & No \\
\hline 10 & Respiratory failure, myelodysplastic syndrome & 68 & 30 & 43 & 5 & 6 & no & Yes \\
\hline 11 & Connective tissue disease & 38 & 29 & 15 & 8 & 0 & no & Yes \\
\hline 12 & Pneumonia & 28 & 29 & 32 & 5 & 1 & no & Yes \\
\hline 13 & Pneumonia (influenza $\mathrm{H}_{1} \mathrm{~N}_{1}$ ) & 45 & 22 & 37 & 4 & 2 & no & Yes \\
\hline 14 & Alveolar hemorrhage & 18 & 24 & 43 & 5 & 4 & no & Yes \\
\hline
\end{tabular}


Table 2 Measured variables

\begin{tabular}{|c|c|c|c|c|c|c|c|}
\hline & BI 1 & BI 2 & $\mathrm{BI} 3$ & VM & HFNC & NIV & $\mathrm{p}$-value \\
\hline $\mathrm{HR}[1 / \mathrm{min}]$ & $90 \pm 23$ & $90 \pm 23$ & $89 \pm 20$ & $87 \pm 21$ & $89 \pm 23$ & $86 \pm 21$ & ns \\
\hline $\mathrm{BP}_{\text {mean }}[\mathrm{mmHg}]$ & $88 \pm 16$ & $90 \pm 15$ & $86 \pm 18$ & $88 \pm 13$ & $90 \pm 16$ & $91 \pm 18$ & ns \\
\hline RR [1/min] & $28 \pm 9$ & $28 \pm 9$ & $26 \pm 7$ & $28 \pm 8^{*}$ & $26 \pm 7$ & $24 \pm 9^{*}$ & $\begin{array}{c}{ }^{*} V M-N I V \\
p<0,01\end{array}$ \\
\hline $\mathrm{SpO}_{2}[\%]$ & $93 \pm 3$ & $92 \pm 6$ & $93 \pm 3$ & $95 \pm 4$ & $96 \pm 3$ & $98 \pm 3$ & ns \\
\hline $\mathrm{pH}$ & $7.47 \pm 0.06$ & $7.46 \pm 0.05$ & $7.46 \pm 0.07$ & $7.46 \pm 0.06$ & $7.46 \pm 0.07$ & $7.44 \pm 0.08$ & ns \\
\hline $\mathrm{PaO} 2[\mathrm{mmHg}]$ & $67 \pm 15$ & $64 \pm 10$ & $66 \pm 10$ & $85 \pm 22^{\#}$ & $101 \pm 34^{* \# \#}$ & $129 \pm 38^{\dagger *}$ & $\begin{array}{c}\text { \#VM-HFNC } \\
p<0,01 \\
{ }^{+} \text {HFNC-NIV } \\
p<0,01 \\
{ }^{*} \text { VM-NIV- } \\
p<0,001\end{array}$ \\
\hline $\mathrm{PaCO} 2[\mathrm{mmHg}]$ & $36 \pm 5$ & $38 \pm 5$ & $37 \pm 5$ & $37 \pm 6$ & $37 \pm 5$ & $39 \pm 7$ & ns \\
\hline Borg scale & $3.6 \pm 2.5$ & $4.3 \pm 3.2$ & $3.9 \pm 2.7$ & $3.3 \pm 2.3$ & $2.9 \pm 2.1^{*}$ & $5.0 \pm 3.3^{*}$ & $\begin{array}{c}{ }^{*} \text { HFNC-NIV } \\
p<0,05\end{array}$ \\
\hline Patient comfort & $2.5 \pm 1.6$ & $4.0 \pm 1.9$ & $4.0 \pm 2.3$ & $3.1 \pm 2.8$ & $2.7 \pm 1.8^{*}$ & $5.4 \pm 3.1^{*}$ & $\begin{array}{c}{ }^{*} \text { HFNC-NIV } \\
p<0,05\end{array}$ \\
\hline Global rating & n. a. & n. a. & n. a. & $3.1 \pm 1.7^{*}$ & $2.3 \pm 1.3 \#$ & $4.5 \pm 1.7 \#^{*}$ & $\begin{array}{c}\text { *VM-NIV } \\
p<0,05 \\
\text { \#HFNC-NIV } \\
p<0,01\end{array}$ \\
\hline
\end{tabular}

Values are presented as means \pm standard deviation, $B$ I baseline, VM Venturi mask, NIV Non-invasive ventilation, HFNC nasal high-flow oxygen, HR heart rate, $B P_{\text {mean }}$ mean arterial blood pressure, $R R$ respiratory rate, $\mathrm{SpO}_{2}$ peripheral oxygen saturation, $\mathrm{PaO} 2$ arterial pressure of oxygen, $\mathrm{PaCO} 2$ arterial partial pressure of carbon dioxide.

In the final global rating, patients gave the best grades to HFNC $(2.3 \pm 1.3)$, followed by VM $(3.1 \pm 1.7$, ns vs. HFNC) and NIV $(4.5 \pm 1.7, \mathrm{p}<0.01$ vs. HFNC and $\mathrm{p}<0.05$ vs. VM). For further treatment, 10 patients (71\%) chose HFNC (exact 95\% CI: $42 \%$ to $92 \%$ ), 3 chose $\mathrm{VM}$, and 1 NIV.

\section{Discussion}

In this study we investigated the effects of controlled oxygen therapy with HFNC compared to Venturi mask and NIV therapy in patients with mild to moderate acute hypoxic respiratory failure. The protocol was designed to compare the short-term effects on gas exchange and cardio-respiratory parameters. We also conducted a subjective patient evaluation of the three oxygen applications.

The $\mathrm{PaO}_{2}$ was the only gas exchange parameter that was significantly affected by the type of oxygen applicator despite an identical $\mathrm{FiO}_{2}$ (0.6). Not surprisingly, the highest $\mathrm{PaO}_{2}$ was observed under NIV, because here the PEEP of $5 \mathrm{~cm} \mathrm{H} \mathrm{H}_{2} \mathrm{O}$ might have led to alveolar recruitment and reduction of intrapulmonary shunt. It has been proposed that HFNC also can lead to some alveolar recruitment [15]. However, in a study by Groves HFNC with a gas flow of $60 \mathrm{l} / \mathrm{min}$. increased airway pressures only up to $2,7 \mathrm{~cm}$
$\mathrm{H}_{2} \mathrm{O}$ while breathing with an open mouth, and $7.4 \mathrm{~cm}$ $\mathrm{H}_{2} \mathrm{O}$ with the mouth closed. This increase in airway pressure was considered negligible [16]. Nevertheless, a recent study of Riera and coworkers [17] shows an increase in end-exspiratory lung volume, messured by electrical impedance tomography (EIT), presumably due to the higher airway pressure levels.

The higher $\mathrm{PaO}_{2}$ observed under HFNC, compared to a Venturi mask, can be explained by the higher administered gas flows (up to $55 \mathrm{l} / \mathrm{min}$ ). With a Venturi mask and an oxygen flow of $15 \mathrm{l} / \mathrm{min}$ the targeted $\mathrm{FiO}_{2}$ of $0.6 \mathrm{can}$ only be achieved when the total gas flow is not higher than $30 \mathrm{~L} / \mathrm{min}$. In acute hypoxic respiratory failure often much higher inspiratory gas flows are generated. Especially in Venturi systems and other masks that are not tight fitting, this leads to an additional room-air admixture during inspiration resulting in a reduction of $\mathrm{FiO}_{2}$ [6].

In our patients with mild to moderate acute hypoxic respiratory failure, all oxygen application systems were able to increase the mean $\mathrm{PaO}_{2}$ into the horizontal upper part of the oxygen binding curve, so that a normal mean arterial oxygen saturation $\left(\mathrm{SaO}_{2}\right)$ of $\geq 95 \%$ could be achieved with all oxygen applicators. This might explain why we did not observe any relevant differences regarding the 
other measured cardiorespiratory parameters (respiratory rate, $\mathrm{PaCO}_{2}$ ) during the short observation period of just 30 minutes. A notable effect on these parameters was found in other studies [11,18-21] of more severe forms of hypoxic respiratory failure. In these studies, differences in the $\mathrm{PaO}_{2}$ attributable to the type of oxygen applicator affect the $\mathrm{SaO}_{2}$ in the steep part of the oxygen binding curve. In such patients, a higher $\mathrm{SaO}_{2}$ might reduce hypoxic respiratory drive. However, patients with these more severe forms of hypoxic respiratory failure were excluded from our study, because they are usually under severe distress and not able to comply with the experimental protocol.

With respect to patient comfort and satisfaction, in our study HFNC received the best subjective ratings regarding dyspnea, discomfort and general evaluation and was preferred by a large majority of the patients for further oxygen supplementation. Compared to Venturi mask, however, the differences were not statistically significant. We hypothesize that improved humidification of the respiratory gas using HFNC might have a minor positive effect on patient comfort. Chanques et al. investigated the effect of an active humidification system compared to a conventional bubble humidifier during oxygen therapy via a face mask using a gas flow of $5-11 \mathrm{l} / \mathrm{min}$. Active humidification resulted in less symptoms of dehydration of the upper respiratory tract and significantly increased comfort for the patients [22]. Cuquemelle et al. similarily showed increased patient comfort when standard oxygen therapy via the nasal airways with no humidification was compared with HFNC with heated and humidified oxygen [8]. The positive effect of HFNC on respiratory gas humidification, however, might be offset by other factors affecting patient comfort such as an increased noise level which often is a problem at least with older HFNC systems. Other studies, however, also have shown that HFNC is well tolerated and effective in relieving dyspnea when compared to oxygen therapy via standard face masks $[11,20]$. In the study by Lenglet et al. patients with acute hypoxic respiratory failure were treated in the emergency department first with a non-rebreathing mask and were then switched to HFNC. HFNC was preferred by $76 \%$ of the healthcare givers.

Our study so far is the first study to compare HFNC with NIV in the setting of acute hypoxic respiratory failure, NIV received the worst subjective ratings in all categories although it led to the best improvement in oxygenation. Three patients terminated the NIV phase of the study early due to intolerance of the application. It should be noted that the adaptation phase to the NIV mask in our protocol was very short. So, it is possible that an individual optimization of the NIV parameters and a longer adaptation phase might have resulted in improved patient tolerance and comfort. However, patients with hypoxic respiratory failure often require prolonged periods of respiratory support, which many patients do not tolerate on NIV. In clinical practice we often use a combination of NIV and HFNC in patients with moderate to severe hypoxic respiratory failure in whom we are trying to avoid intubation (e.g. immunocompromised patients) $[23,24]$. A beneficial effect of NIV on dyspnea has also been shown in end-of-life patients with solid tumors, however, it was not compared to HFNC in this study setting [25]. Intermittent phases with HFNC helped to prevent skin damage, allow the patients to cough, eat, and communicate, and thus might increase patient compliance.

Our study was designed as a short term experimental study and therefore has several limitations. The duration of the interventions was with 30 minutes very short. Longer durations, however, would have made direct comparisons of the measurements more difficult. In addition, for patients in acute respiratory distress it was problematic to comply with a longer experimental protocol. Our study did not address questions regarding the correct indication for HFNC and its long-term effects. Several recent studies have demonstrated that HFNC can be applied safely in many patients with acute hypoxic respiratory failure including influenza H1N1 pneumonia $[20,21]$. Patients with severe respiratory failure, however, may still require mechanical ventilation. A recent experimental study showed that in mild lung injury spontaneous breathing improved lung recruitment. In severe lung injury, however, accelerated spontaneous ventilation induced more lung injury than lung-protective mechanical ventilation including muscle paralysis. High tidal volumes under spontaneous ventilation led to high transpulmonary pressures with significant stress and strain on the injured lung. The lack of a PEEP also promoted atelectasis and cyclic alveolar collapse. Finally, application of a high $\mathrm{FiO}_{2}$ up to 1.0, which is possible with HFNC, might further accelerate lung injury [26].

\section{Conclusion}

HFNC is a well tolerated and an effective device for oxygen therapy in mild to moderate hypoxic respiratory failure and bridges the gap between conventional oxygen applicators, NIV, and invasive mechanical ventilation. The indications and contraindications for HFNC have to be further clarified in additional clinical outcome studies.

\section{Abbreviations}

HFNC: High-flow nasal cannula; NIV: Non-invasive ventilation; VM: Venturi mask; $\mathrm{PaO}_{2}$ : Partial pressure of oxygen in arterial blood; $\mathrm{FiO}_{2}$ : Fraction of oxygen in inspired air; $\mathrm{ElO}_{2}$ : Effective inspiratory oxygen concentration; PEEP: Positive end-expiratory pressure; COPD: Chronic obstructive pulmonary disease; PDMS: Patient Data Management System; ANOVA: Analysis of variance; $\mathrm{BI}$ : Baseline; HR: Heart rate; $\mathrm{BP}_{\text {mean }}$ : Mean arterial blood pressure; RR: Respiratory rate; $\mathrm{SpO}_{2}$ : Peripheral oxygen saturation; $\mathrm{PaO} 2$ : Arterial partial pressure of oxygen; PaCO2: Arterial partial pressure of carbon dioxide. 


\section{Competing interests}

Fisher \& Paykl provided two Optiflow-devices at no charge for the study. Otherwise the investigators received no financial support for the study and the company was not involved in data analysis and publication of the study.

\section{Authors' contributions}

NS. Conception and design of the study, data acquisition, data analysis, manuscript drafting BB. Conception and design of the study, data acquisition, data analysis, manuscript editing GB. Conception and design of the study, data analysis, statistics, manuscript editing $\mathrm{MH}$. Recruitement of subjects for the study, data acquisition, manuscript drafting, manuscript editing $\mathrm{JH}$. Conception and design of the study, data analysis, manuscript editing RR. Conception and design of the study, recruitement of subjects, data analysis, manuscript editing. All authors read and approved the final manuscript.

\section{Acknowledgements}

We would like to thank Dr. Andrew Levinson for critical comments and revising the manuscript.

\section{Author details}

'Department of Internal Medicine, Medical Intensive Care Unit, University of Tübingen, Otfried-Müller-Str, 10, Tübingen 72076, Germany. ${ }^{2}$ Department of Clinical Epidemiology and Applied Biometry, University of Tübingen, Tübingen, Germany. ${ }^{3}$ Department of Internal Medicine, Division of Pulmonary Medicine, University of Tübingen, Tübingen, Germany.

Received: 22 December 2013 Accepted: 25 July 2014

Published: 7 August 2014

\section{References}

1. O'Driscoll BR, Howard LS, Davison AG: BTS guideline for emergency oxygen use in adult patients. Thorax 2008, 63(Suppl 6):vi1-vi68.

2. Armstrong JAM, Guleria A, Girling K: Evaluation of gas exchange deficit in the critically ill. Contin Educ Anaesth Crit Care Pain 2007, 7(4):131-134.

3. Kallstrom TJ: AARC Clinical Practice Guideline: oxygen therapy for adults in the acute care facility-2002 revision \& update. Respir Care 2002, 47(6):717-720

4. El Khatib MF: High-flow nasal cannula oxygen therapy during hypoxemic respiratory failure. Respir Care 2012, 57(10):1696-1698.

5. Wagstaff TA, Soni N: Performance of six types of oxygen delivery devices at varying respiratory rates. Anaesthesia 2007, 62(5):492-503.

6. Sim MA, Dean P, Kinsella J, Black R, Carter R, Hughes M: Performance of oxygen delivery devices when the breathing pattern of respiratory failure is simulated. Anaesthesia 2008, 63(9):938-940

7. Corley A, Caruana LR, Barnett AG, Tronstad O, Fraser JF: Oxygen delivery through high-flow nasal cannulae increase end-expiratory lung volume and reduce respiratory rate in post-cardiac surgical patients. $\mathrm{Br} J$ Anaesth 2011, 107(6):998-1004.

8. Cuquemelle E, Pham T, Papon JF, Louis B, Danin PE, Brochard L: Heated and humidified high-flow oxygen therapy reduces discomfort during hypoxemic respiratory failure. Respir Care 2012, 57(10):1571-1577.

9. Chidekel A, Zhu Y, Wang J, Mosko JJ, Rodriguez E, Shaffer TH: The effects of gas humidification with high-flow nasal cannula on cultured human airway epithelial cells. Pulm Med 2012, 2012:380686.

10. Ricard JD: High flow nasal oxygen in acute respiratory failure. Minerva Anestesiol 2012, 78(7):836-841.

11. Lenglet H, Sztrymf B, Leroy C, Brun P, Dreyfuss D, Ricard JD: Humidified high flow nasal oxygen during respiratory failure in the emergency department: feasibility and efficacy. Respir Care 2012, 57(11):1873-1878.

12. Bello G, De Pascale G, Antonelli M: Noninvasive ventilation: practical advice. Curr Opin Crit Care 2013, 19(1):1-8.

13. Ferrer M, Esquinas A, Leon M, Gonzalez G, Alarcon A, Torres A: Noninvasive ventilation in severe hypoxemic respiratory failure: a randomized clinical trial. Am J Respir Crit Care Med 2003, 168(12):1438-1444.

14. Schonhofer B, Kuhlen R, Neumann P, Westhoff M, Berndt C, Sitter H: Noninvasive ventilation as treatment for acute respiratory insufficiency. Essentials from the new S3 guidelines. Anaesthesist 2008, 57(11):1091-1102.

15. Dysart K, Miller TL, Wolfson MR, Shaffer TH: Research in high flow therapy: mechanisms of action. Respir Med 2009, 103(10):1400-1405.
16. Groves N, Tobin A: High flow nasal oxygen generates positive airway pressure in adult volunteers. Aust Crit Care 2007, 20(4):126-131.

17. Riera J, Perez P, Cortes J, Roca O, Masclans JR, Rello J: Effect of high-flow nasal cannula and body position on end-expiratory lung volume: a cohort study using electrical impedance tomography. Respir Care 2013, 58(4):589-596.

18. Roca O, Riera J, Torres F, Masclans JR: High-flow oxygen therapy in acute respiratory failure. Respir Care 2010, 55(4):408-413.

19. Sztrymf B, Messika J, Mayot T, Lenglet H, Dreyfuss D, Ricard JD: Impact of high-flow nasal cannula oxygen therapy on intensive care unit patients with acute respiratory failure: a prospective observational study. J Crit Care 2012, 27(3):324-13.

20. Sztrymf B, Messika J, Bertrand F, Hurel D, Leon R, Dreyfuss D, Ricard JD: Beneficial effects of humidified high flow nasal oxygen in critical care patients: a prospective pilot study. Intensive Care Med 2011 37(11):1780-1786.

21. Rello J, Perez M, Roca O, Poulakou G, Souto J, Laborda C, Balcells J, Serra J, Masclans JR: High-flow nasal therapy in adults with severe acute respiratory infection: a cohort study in patients with 2009 influenza A/ H1N1v. J Crit Care 2012, 27(5):434-439.

22. Chanques $G$, Constantin JM, Sauter M, Jung B, Sebbane M, Verzilli D, Lefrant $J Y$, Jaber S: Discomfort associated with underhumidified high-flow oxygen therapy in critically ill patients. Intensive Care Med 2009, 35(6):996-1003.

23. Razlaf P, Pabst D, Mohr M, Kessler T, Wiewrodt R, Stelljes M, Reinecke $H$, Waltenberger J, Berdel WE, Lebiedz P: Non-invasive ventilation in immunosuppressed patients with pneumonia and extrapulmonary sepsis. Respir Med 2012, 106(11):1509-1516.

24. Bello G, De Pascale G, Antonelli M: Noninvasive ventilation for the immunocompromised patient: always appropriate? Curr Opin Crit Care 2012, 18(1):54-60

25. Nava S, Ferrer M, Esquinas A, Scala R, Groff P, Cosentini R, Guido D, Lin CH, Cuomo AM, Grassi M: Palliative use of non-invasive ventilation in end-oflife patients with solid tumours: a randomised feasibility trial. Lancet Oncol 2013, 14(3):219-227.

26. Altemeier WA, Sinclair SE: Hyperoxia in the intensive care unit: why more is not always better. Curr Opin Crit Care 2007, 13(1):73-78.

doi:10.1186/1471-2253-14-66

Cite this article as: Schwabbauer et al:: Nasal high-flow oxygen therapy in patients with hypoxic respiratory failure: effect on functional and subjective respiratory parameters compared to conventional oxygen therapy and non-invasive ventilation (NIV). BMC Anesthesiology 2014 14:66

\section{Submit your next manuscript to BioMed Central and take full advantage of:}

- Convenient online submission

- Thorough peer review

- No space constraints or color figure charges

- Immediate publication on acceptance

- Inclusion in PubMed, CAS, Scopus and Google Scholar

- Research which is freely available for redistribution 